\title{
SPATIO-TEMPORAL MAPPING AND ANALYSIS OF MANGROVE EXTENTS AROUND MANILA BAY USING LANDSAT SATELLITE IMAGERY AND MANGROVE VEGETATION INDEX (MVI)
}

\author{
M. Conopio ${ }^{1}$, A.B Baloloy ${ }^{1}$, J. Medina ${ }^{1,2}$, A.C. Blanco ${ }^{1,2}$ \\ ${ }^{1}$ UP Training Center for Applied Geodesy and Photogrammetry - Diliman, Quezon City, Philippines \\ ${ }^{2}$ Department of Geodetic Engineering, University of the Philippines Diliman, Quezon City, Philippines \\ mmconopio@up.edu.ph, alvinbbaloloy@gmail.com,jmmedina@up.edu.ph, acblanco@up.edu.ph,
}

KEY WORDS: Landsat, Manila Bay, Mangrove, Mangrove Vegetation Index, remote sensing, GIS

\begin{abstract}
:
Mangroves are considered one of the most undervalued ecosystems in the world. It provides shelter to a wide range of species and protection from natural hazards to coastal communities. The Philippines, being a country with long coastlines, benefits greatly from mangroves. Historically, it had 400,000-500,000 hectares of mangroves forest in 1920, which declined to 120,000 hectares in 1994 due to rapid industrialization, particularly the conversion of these forests into aquaculture such as fishponds Mangrove forest in the Philippines saw a rapid decline between 1920 and 1994 due to aquaculture conversion and land reclamation Mangrove Vegetation Index (MVI), an established mangrove detection algorithm, was applied on Landsat satellite images of Manila Bay to map the extent of the mangrove forest from 1990 to 2020. Thirteen time-series maps were produced. Area computation showed that the coastline of Bulacan had the most mangroves, while the coastline of Metro Manila had the least throughout the years.
\end{abstract}

\section{INTRODUCTION}

Mangroves are forested wetlands that are found in coastal areas of the tropics and subtropics (Craft, 2016). They are considered as one of the most undervalued ecosystems in the world. Besides giving homes to a wide range of species, most of which are endangered, they also provide a number of goods and services to coastal communities (Duke, et al., 2014). The Philippines has a significant number of mangrove forests. The country alone contains $50 \%$ of mangrove species in the world (Garcia et al., 2013). It was even considered as one of the top 15 countries rich in mangroves (Long and Giri, 2011).

The Philippines benefits greatly from mangrove forests. The country is very susceptible to typhoons which can cause great damage to coastal areas. Mangrove forests act as the first line of defense against natural hazards such as storm surges, tsunamis, and coastal erosion. Many research studies have been conducted to highlight the significance of mangrove forests for the protection of coastal communities. A study conducted by Mendoza and Alura (2001) showed that it is most likely that agricultural plantations, such as coconut trees, near coastal areas can be easily uprooted during a storm if there are no mangroves in the area. According to Harada, et al. (2002), mangroves are as effective as a concrete seawall against coastal damages caused by tsunamis and strong waves. As climate change worsens and its effects becomes more devastating, the Philippines needs mangroves more than ever before. But the country is experiencing a rapid decline in mangrove forests, most of which is due to conversion to fishponds and other aquacultures (Primavera, 2000). According to Primevera (2000), the
Philippines initially had 400,000-500,000 ha of mangrove forest in 1920, and this declined to 120,000 ha in 1994.

Remote sensing has become a powerful tool for environmental monitoring since it provides an efficient and practical way of analysis using satellite images. Long, et al. (2014) used Landsat imageries and remote sensing techniques to map the spatial distribution of mangroves in the Philippines in the year 1990, 2000, and 2010. A recent study by Baloloy et al (2020) developed a new index, Mangrove Vegetation Index (MVI), for fast and accurate mangrove mapping. With the declining extent of mangroves, research like this is very valuable in developing conservation and rehabilitation strategies and for future analyses.

\section{REVIEW OF RELATED LITERATURE}

There are many ways to visualize mangroves using satellite imagery. Band combination is commonly used to easily distinguish mangroves in an image. There are many band combinations that can be used, each shows mangrove in a different way. In a comparison conducted by Pagkalinawan (2015), a true color composite (R-G-B) of a Landsat 8 mangrove scene was compared to a false color composite (NIR-SWIR1SWIR2) (Figure 1). 

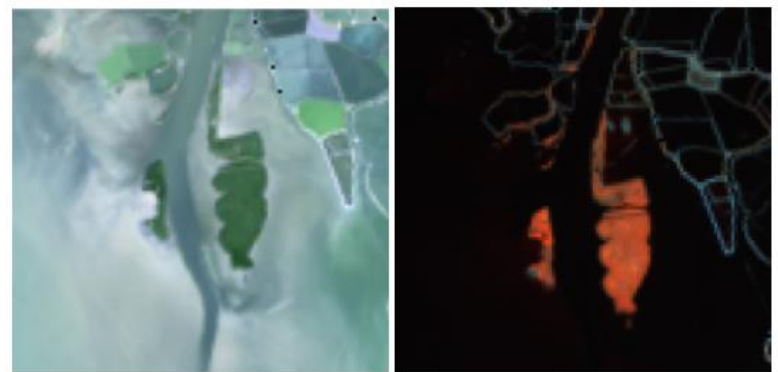

Figure 1. Band Combination Comparison. True Color (R-G-B), (left), False Color (NIR-SWIR1-SWIR2) (right).

In the true color composite, the mangroves have a darker green hue than the other vegetation while in the false color composite, the mangroves were represented in a bright red orange hue. Based on the comparison, the false color composite did a better job of properly distinguishing mangroves from other vegetation. Similar results were obtained using the false color combination (NIR-SWIR1-RED) (Baloloy et al., 2020) (Figure 2).

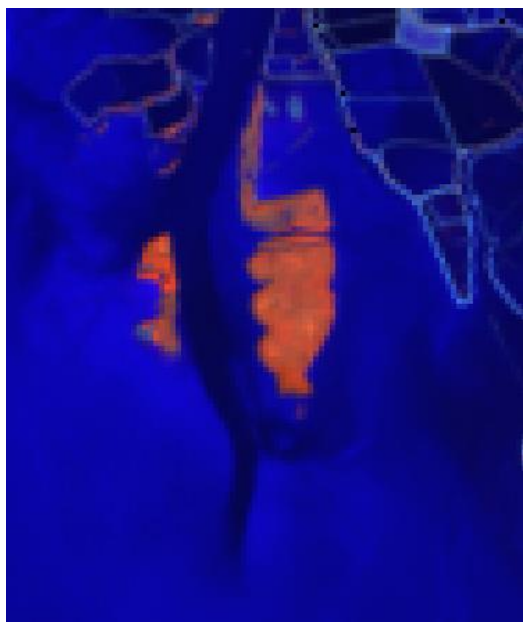

Figure 2. False Color Composite (NIR- SWIR1-RED)

Band indices are also used to distinguish mangroves in an image. A study conducted by Baloloy et al. (2020) developed a new index named Mangrove Vegetation Index (MVI) for a rapid and accurate mangrove mapping using satellite imagery. The MVI utilizes the NIR, SWIR and Green bands. The index considers the distinct greenness and moisture of mangroves to discriminate it from other types of vegetation and land cover (Equation 1).

$$
M V I=\frac{N I R-\text { Green }}{S W I R-\text { Green }}
$$

where $\mathrm{MVI}=$ Mangrove Vegetation Index

$\mathrm{NIR}=$ Near Infrared Band

Green $=$ Green Band

SWIR $=$ Short-wave Infrared Band

Training samples were conducted to determine the appropriate threshold to be used for the MVI. Using 50 pure training samples representing mangroves, the minimum mangrove MVI value is 4.5 and the maximum value is 16.5 . This threshold value though is not absolute and can change depending on other factors such as health of mangrove, physical aspect of the location etc.

\section{METHODOLOGY}

Figure 3 shows the general flowchart of the methodology which consists of three major steps, namely data gathering, data processing, and data output.

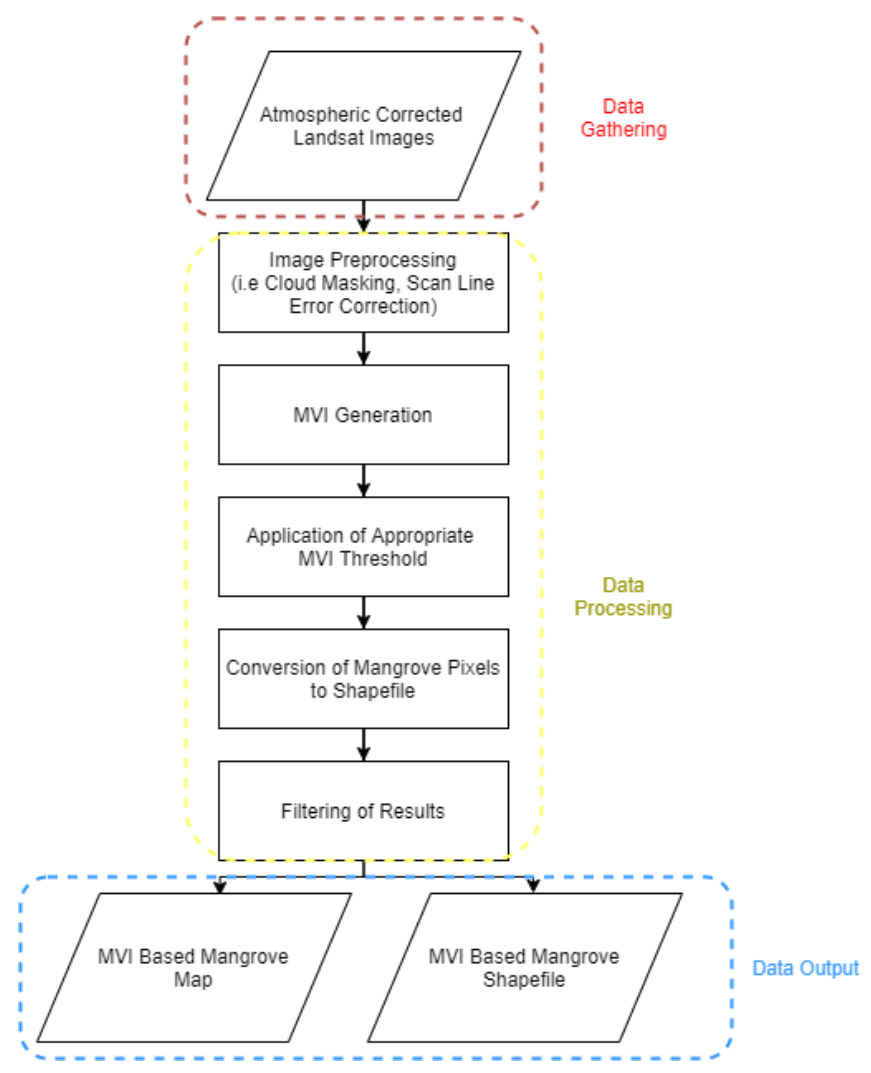

Figure 3. General methodology

\subsection{Data Gathering}

Landsat satellite images with 30 meters resolution covering Manila Bay (Figure 4) were downloaded from the U.S. Geological Survey (USGS) Earth Resources Observation and Science Center (http://glovis.usgs.gov). Images with less than $20 \%$ cloud cover were selected. The summary of the downloaded datasets is shown in Table 1. 


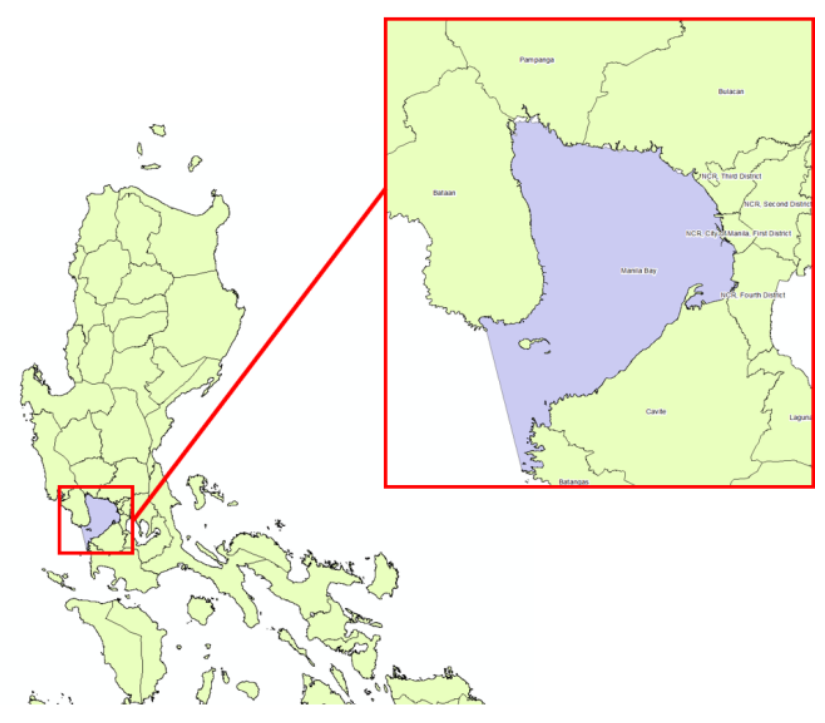

Figure 4. Manila Bay Area

\begin{tabular}{|c|c|c|}
\hline Year & Date & Source \\
\hline $\begin{array}{l}\text { Older } \\
\text { Years }\end{array}$ & $\begin{array}{c}1947- \\
1953\end{array}$ & NAMRIA \\
\hline \multirow{4}{*}{1990} & 20-Jan & \multirow{4}{*}{ Landsat 5} \\
\hline & 25-Mar & \\
\hline & 12-May & \\
\hline & 15-Jul & \\
\hline \multirow{7}{*}{1995} & 18-Jan & \multirow{7}{*}{ Landsat 5} \\
\hline & 19-Feb & \\
\hline & 07-Mar & \\
\hline & 23-Mar & \\
\hline & 08-Apr & \\
\hline & 26-May & \\
\hline & 27-Jun & \\
\hline \multirow{2}{*}{2000} & 05-Apr & \multirow{2}{*}{ Landsat 5} \\
\hline & 15-Nov & \\
\hline 2002 & 03-Apr & Landsat 7 \\
\hline \multirow{4}{*}{2004} & 04-Feb & \multirow{4}{*}{ Landsat 7} \\
\hline & 24-Apr & \\
\hline & 26-May & \\
\hline & 13-Jul & \\
\hline \multirow{6}{*}{2006} & $25-\mathrm{Feb}$ & \multirow{6}{*}{ Landsat 7} \\
\hline & 29-Mar & \\
\hline & 14-Apr & \\
\hline & 01-Jun & \\
\hline & 24-Nov & \\
\hline & 26-Dec & \\
\hline
\end{tabular}

\begin{tabular}{|c|c|c|}
\hline Year & Date & Source \\
\hline \multirow{3}{*}{2008} & 20-Jan & \multirow{3}{*}{ Landsat 7} \\
\hline & 18-Mar & \\
\hline & 19-Apr & \\
\hline \multirow{4}{*}{2010} & 04-Feb & \multirow{4}{*}{ Landsat 7} \\
\hline & 08-Mar & \\
\hline & 24-Mar & \\
\hline & 12-Jun & \\
\hline \multirow{6}{*}{2012} & 26-Feb & \multirow{6}{*}{ Landsat 7} \\
\hline & 14-Apr & \\
\hline & 30-Apr & \\
\hline & 23-Oct & \\
\hline & 24-Nov & \\
\hline & 10-Dec & \\
\hline 2014 & 07-Feb & Landsat 8 \\
\hline \multirow{5}{*}{2016} & 13-Feb & \multirow{5}{*}{ Landsat 8} \\
\hline & 16-Mar & \\
\hline & 17-Apr & \\
\hline & 03-May & \\
\hline & 19-May & \\
\hline \multirow{4}{*}{2018} & 06-Mar & \multirow{4}{*}{ Landsat 8} \\
\hline & 09-May & \\
\hline & 25-May & \\
\hline & 03-Dec & \\
\hline \multirow{4}{*}{2020} & 23-Jan & \multirow{4}{*}{ Landsat 8} \\
\hline & 30-May & \\
\hline & 01-Jul & \\
\hline & 17-Jul & \\
\hline
\end{tabular}

Table 1. Dataset Summary.

For years older than 1990, mangrove data, in shapefile format, were obtained from PhilGIS (https://philgis.org/). These mangrove data were derived from NAMRIA 1:50,000 topographic maps that were originally published by the US Army Service using aerial photographs.

All downloaded Landsat images were atmospherically corrected. The acquired Landsat 7 images all had scan line error due to the failure of the satellite's Scan Line Corrector (SLC) during its mission (Figure 5).
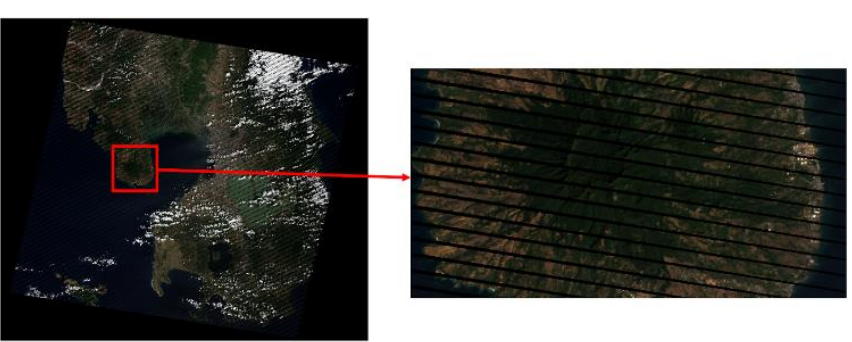

Figure 5. Scan Line Error (SLC)

\subsection{Data Processing}

3.2.1 Image Pre-processing: Image pre-processing was done in QGIS software. All bands for each image were stacked as one file using the Merge tool. Cloud masking was then performed on all stacked images using the raster calculator and the Quality Bands of each image (Figure 6).
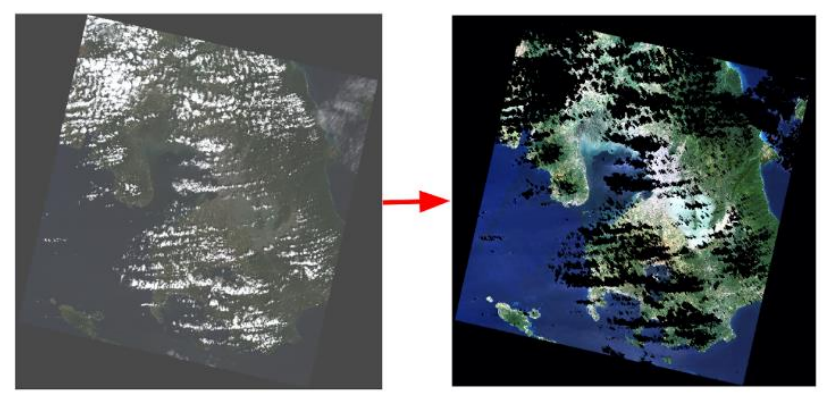

Figure 6. Cloud masking of Landsat images

For Landsat 7 images, the Fill nodata tool was used to correct the scan line error. This tool fills in raster regions with no data values by interpolation from edges. The resulting images were exported as TIFF files.

3.2.2 MVI Application: The MVI equation (Baloloy et al., 2020) (Equation 1) was applied to the images using QGIS Raster Calculator tool. Pixels with MVI in the range 4-20 were selected as mangrove pixels. This threshold was based on Baloloy et al. (2019) the application of the MVI on training pixels representing pure sample of the selected class. The resulting images were then exported as shapefiles.

3.2.3 Filtering: Additional filtering was conducted to remove misclassified/noise data. This was done by overlaying the shapefile to the false color composite (NIR, SWIR1, RED) image (Figure 7). Pixels that have a bright orange color are considered mangroves. 


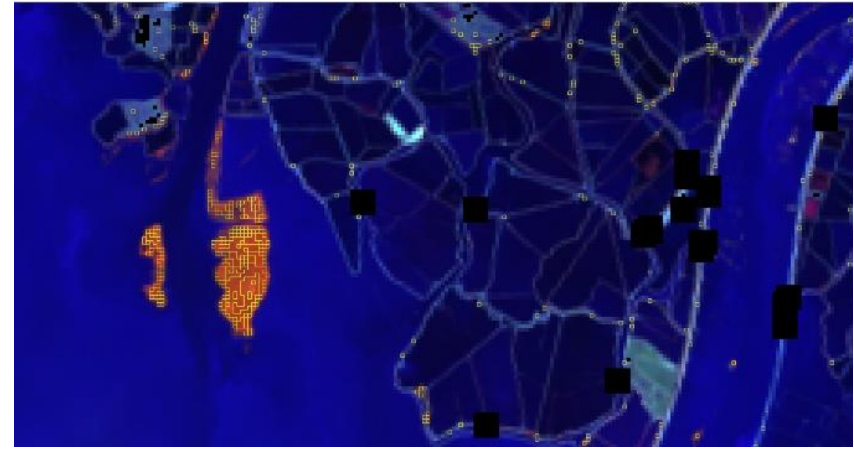

Figure 7. False color composite showing mangroves

\subsection{Data Output}

MVI-derived mangrove shapefiles for each year were merged and time-series mangrove maps were generated for Manila Bay.

\section{RESULTS AND DISCUSSION}

The MVI was able to consistently detect dense mangrove forests (Figure 8). Thin and small patches of mangroves were not consistently detected, because of limitation due to the images' spatial resolution and other factors such as mangrove density and tide level. . Accuracy assessment of MVI was done by Baloloy, et al. (2020) on different study sites using high resolution drone orthophotos and mangrove field inventory. The orthophotos have a spatial resolution of 3 to $5 \mathrm{~cm}$ and covered the mangroves areas from their study sites. The overall accuracy of the MVI is $92 \%$.
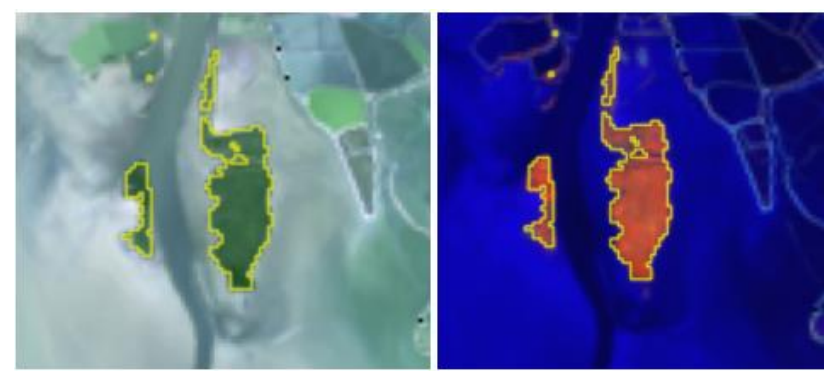

Figure 8. Detected Dense Mangrove Forest

The MVI also produced some misclassified/noise data, more particularly pixels terrestrial vegetation near water and the edges of fishponds (Figure 9). This noise can be attributed to the resolution of the satellite imagery and the threshold used for the MVI generation.
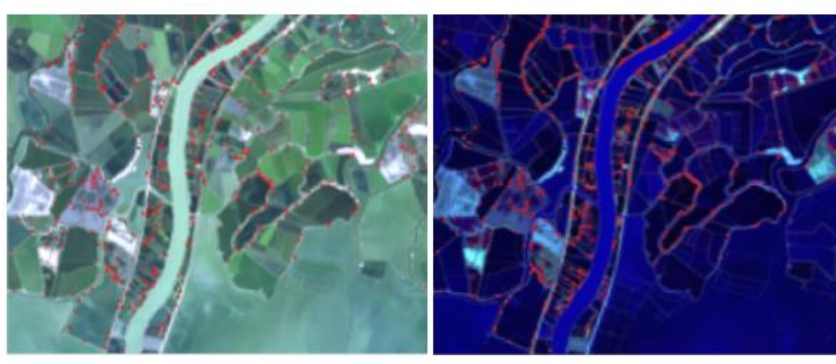

Figure 10 shows the mangrove in the Manila Bay coastline in the year 2020.

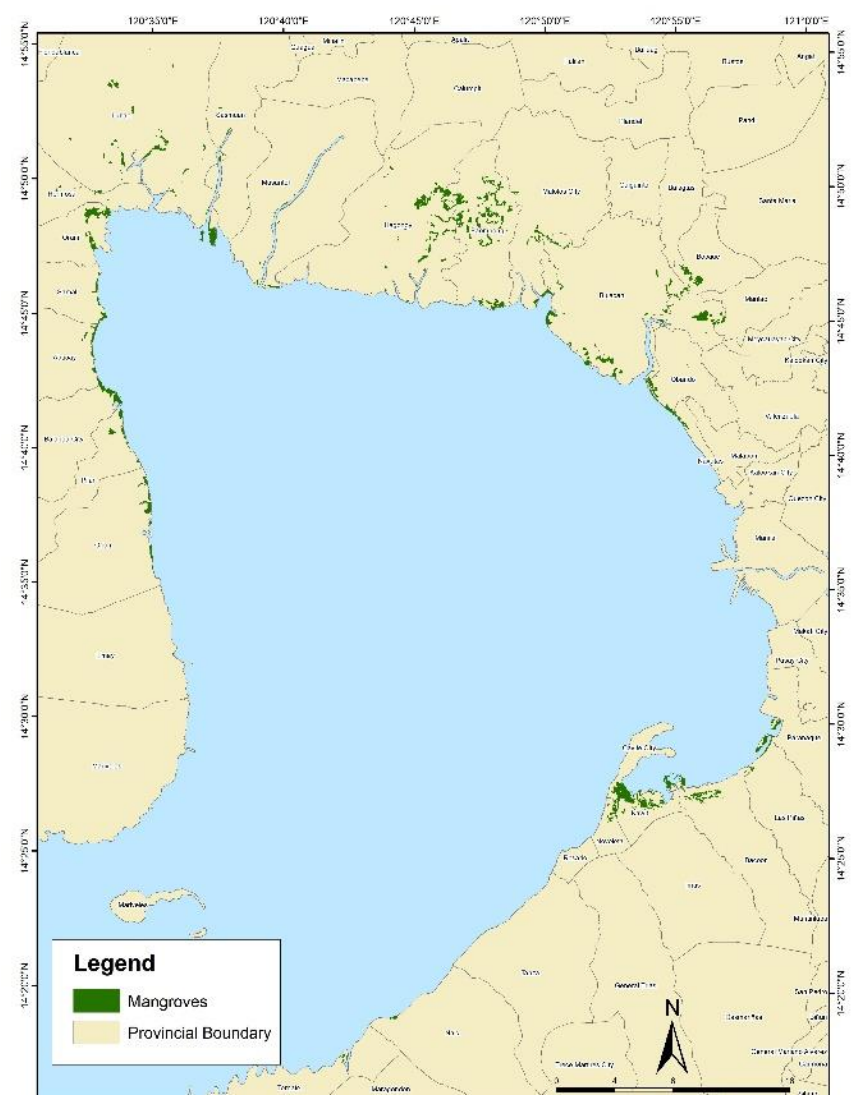

Figure 10. Sample map output

The area in hectares of the mangroves per year is shown in figure 11. The mangrove map obtained from NAMRIA topographic map, which shows the mangroves for years earlier than 1990, only shows the mangrove on the outer coastlines which explains the lower area compared to other years. Figure 7 shows that the trend of mangrove areas in Manila Bay is undulating from 1990 to 2020 .

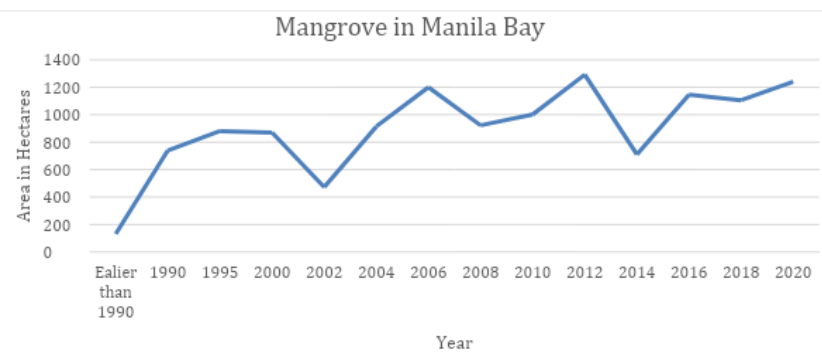

Figure 11. Area of mangroves in Manila Bay per year

The area of mangroves per province is shown in Figure 12. Based on the final output, the coastlines of Bulacan have the greatest number of mangroves while the coastlines of the Metro Manila have the least number of mangroves.

Figure 9. Misclassified/Noise Data. 


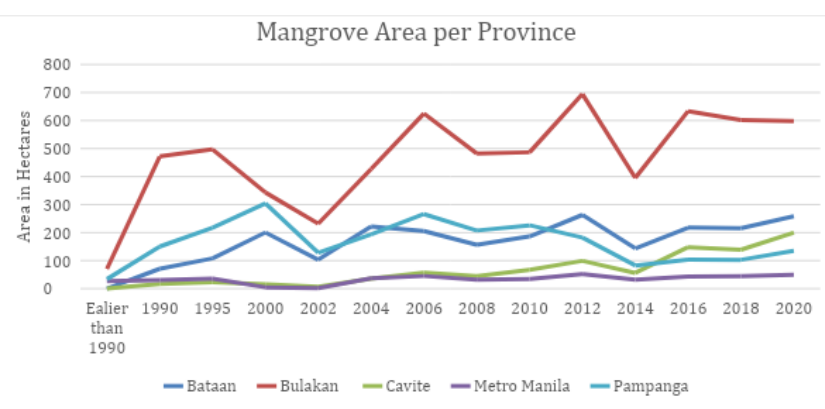

Figure 12. Area of mangroves per province

According to Primavera (2000), one of the key reasons for the decline in mangroves are the conversion of mangrove areas to other land use such as aquaculture. From Figure 8, Bulacan had the biggest decline in mangrove forest. From 1995 to 2002, the mangrove in Bulacan declined by $53.29 \%$. The province relies heavily on aquaculture as a source of income and has one of the largest hectarage of brackish water ponds in the country (Samson et al., 2011).

Besides the conversion of mangrove forests to aquaculture, land reclamation also contributes to the loss of mangroves in Manila Bay. One of the recent constructions is in Kawit Cavite. Figure 39 shows the Landsat 8 images in 2018 and 2020 of the area. MVI was applied in both images and the result shows that a mangrove forest (highlighted in yellow) in the area in 2018 no longer existed after the completion of the establishment in 2020 (Figure 13).

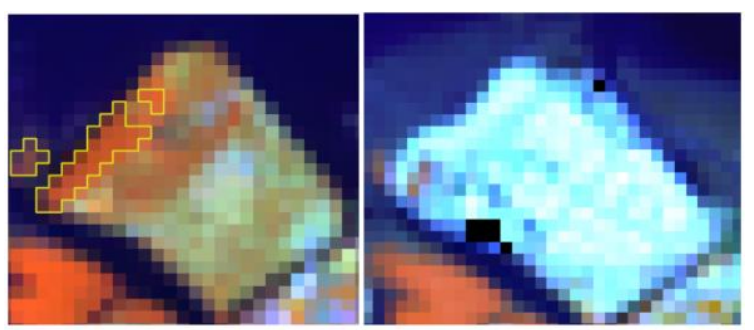

Figure 13. Construction in 2018 (left) and in 2020 (right).

The results of the output were also compared to similar studies conducted by Long, et al. Figure 14 shows the comparison of the area computed from the MVI mangroves maps and the mangrove map created by Long, et al. for the years 1990, 2000, and 2010.

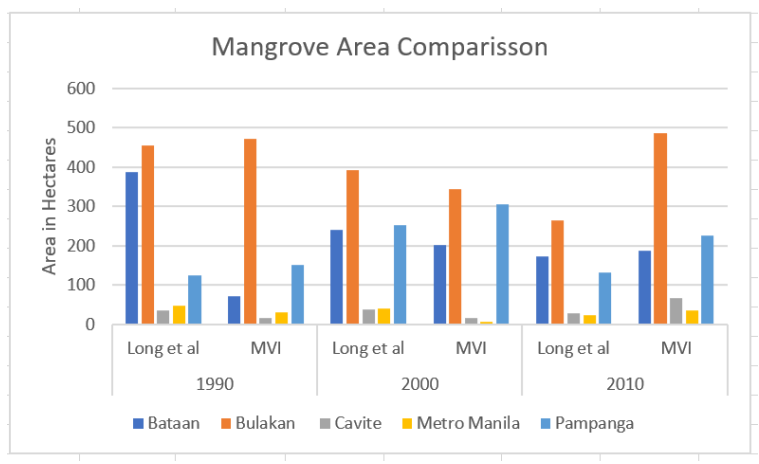

\section{CONCLUSION}

Application of Mangrove Vegetation Index (MVI) for spatiotemporal mangrove mapping in Manila Bay area shows that the density of the mangroves is undulating throughout 1990 to 2020 , with Bulakan province having the biggest area of mangroves. The MVI was able to detect dense mangrove forest while struggling to detect small patches of mangroves. The results of this study show the potential of MVI for fast mangrove mapping and monitoring of Manila Bay

\section{ACKNOWLEDGMENT}

This research was done as part of the Development of Integrated Mapping, Monitoring, and Analytical Network System for Manila Bay and Linked Systems Project (MapABLE) project which is implemented by the University of the Philippines Training Center for Applied Geodesy and Photogrammetry (TCAGP). The project is a component of a DOST-PCIEERD funded research titled "Integrated Mapping, Modelling, and Management System for Manila Bay and Linked System (IM4ManilaBay) Program.

\section{REFERENCES}

Baloloy, A. B., Blanco, A. C., Ana, R. R., \& Nadaoka, K. (2020). Development and application of a new mangrove vegetation index (MVI) for rapid and accurate mangrove mapping. ISPRS Journal of Photogrammetry and Remote Sensing, 166, 95-117.doi:10.1016/j.isprsjprs.2020.06.001

Craft, C. (2016). Mangroves. Creating and Restoring Wetlands, 233-263.

Duke, N., Nagelkerken, I., Agardy, T., Wells, S., \& Lavieren, H. (2014). THE IMPORTANCE OF MANGROVES TO PEOPLE: A CALL TO ACTION.

Garcia, K. B., Malabrigo, P. L., \& Gevaña, D. T. (2013). Philippines' Mangrove Ecosystem: Status, Threats and Conservation. Mangrove Ecosystems of Asia, 81-94. doi:10.1007/978-1-4614-8582-7_5

Harada, K., Imamura, F., \& Hiraishi, T. (2002). Study On The Effect In Reducing Tsunami By The Coastal Permeable Structures. Advances in Hydraulics and Water Engineering. doi:10.1142/9789812776969_0168

Long, J., Napton, D., Giri, C., \& Graesser, J. (2014). A Mapping and Monitoring Assessment of the Philippines' Mangrove Forests from 1990 to 2010. Journal of Coastal Research, 294, 260-271. doi:10.2112/jcoastres-d-13-00057.1

Mendoza A, Alura D (2001) Mangrove structure on the eastern coast of Samar Island, Philippines (pp 423-425). In: DE Stott, RH Mohtar, GC Steinhard (eds) Sustaining the global farm. Selected papers from the 10th International Soil Conservation Organization Meeting held May 24-29, 1999 at Purdue University and the USDA-ARS National Soil Erosion Research Laboratory

Figure 14. Mangrove Area Comparison 
Pagkalinawan, H. (2015). A. Mangrove Forest Mapping using Landsat 8 Imageries. State of the Mangrove Summit:

Northwestern Luzon Proceedings, 60.

doi:10.13185/sm2014.00117

Primavera, J. (2000). Development and conservation of Philippine mangroves: Institutional issues. Ecological

Economics, 35(1), 91-106. doi:10.1016/s0921-8009(00)00170-1

Samson, M \& Rollon,R (2011) Mangrove Revegetation

Potentials of Brackish-Water Pond Areas in the Philippines.

Doi: $10.5772 / 28222$ 